\title{
Cardiopulmonary Index of Organism Adaptation to Low Physical Exercises of Increasing Power
}

\author{
Sergey V. Kupriyanov ${ }^{1 \star}$, Sergey V. Bochkarev ${ }^{1}$, Ludmila M. Semenova ${ }^{1}$, Nikolay Y. Kruglikov ${ }^{1}$, Irina A. Myasnikova ${ }^{1}$, \\ Daria I. Nizova ${ }^{1}$, Nadezhda V. Zhuravleva ${ }^{1}$
}

${ }^{1}$ Chuvash State University named after I.N. Ulyanov, Cheboksary, RUSSIA

*Corresponding Author: kuper-SV@yandex.ru

Citation: Kupriyanov SV, Bochkarev SV, Semenova LM, Kruglikov NY, Myasnikova IA, Nizova DI, Zhuravleva NV. Cardiopulmonary Index of Organism Adaptation to Low Physical Exercises of Increasing Power. Electron J Gen Med. 2020;17(5):em244. https://doi.org/10.29333/ejgm/8217

ARTICLE INFO

Received: 12 Feb. 2020

Accepted: 16 Apr. 2020

\begin{abstract}
Objective. The main purpose of the research was to develop a coefficient of cardiorespiratory system status, which will take into account both frequency and power characteristics of external respiration and hemodynamics activity. Compare an informativeness of this coefficient with a universally accepted Hildebrandt one.

Materials and Methods. 154 apparently healthy young people of both sexes were examined. On a bicycle ergometer with a pedaling rhythm of 40 per minute, five standard stages of short-term physical exercise load ranging from negligible to moderate were provided. Spirography, tonometry and pulsometry were carried out before loading, at its peak and after it. The parameters specified were recorded for each subject simultaneously. Systolic volume was calculated using Starr formula with subsequent defining cardiac minute output.

Statistical analysis was performed using Statistica ${ }^{\circledR} 7.0$ package (StatSoft Inc., USA). Assessment of results' significance was calculated using Student's t-test and sign test.

Results. In the case of low short-term physical exercises pulmonary ventilation is increased due to greater reactivity of external breathing amplitude and to a lesser extent due to change in the frequency of respiratory movements. This type of reactions of the respiratory component in cardiorespiratory interaction is more efficient. In the given conditions, body's adaptation is ensured by breathing component dominance, while responses of systemic arterial pressure and pulse turn out to be less pronounced, less stabile. Taking into account greater adaptive importance in power characteristics changes of respiratory and cardiovascular activity, a coefficient of cardiorespiratory system status is proposed - MBV/RMV (ratio of minute blood flow volume to respiratory minute volume). The given factor is demonstrated to have significantly greater informative value and sensitivity to generally recognized Hildebrandt coefficient.
\end{abstract}

Keywords: cardiorespiratory system, cardiorespiratory index, the Hildebrandt coefficient, minimum exercise, bicycle exercise

\section{INTRODUCTION}

The cardiorespiratory functional system (CRS) provides the body with a unique opportunity to change the most important homeostatic parameters - blood aeration, blood carbon dioxide content, $\mathrm{pH}$, gas exchange at the tissue level, and other constants - by voluntary influencing the respiratory component. The role of the CRS respiratory component in achieving the adaptive result is extremely important. As N. A. Agajanyan puts it, the CRS is "... a universal indicator of the organism's functional reserves and adaptive functions..." (1). The existing close relationship between the respiratory and circulatory systems is well known, it determines the possibility of their mutual compensation when a change in the activity of one of these systems is inevitably associated with the reaction of the other one (2-6). Taking into account an exceptional significance of this interaction, the study of cardiorespiratory interaction in various conditions continues to attract the attention of researchers (7-10, just to name a few).
Physiologists' understanding is increasingly shifting from the initial denial that the CRS exists as an independent functional unit, towards understanding an exceptional significance of its adaptive role (11-15). In previous articles (1617), we have described a number of distinctions and disadvantages in studying this problem at the current stage. $P$. K. Anokhin's understanding a body as a total activity of its functional systems has been recognized mainly among physiologists and is not well known to medical practitioners. It is up-to-date to develop functional systemic criteria and indices that make it possible to evaluate the CRS state both in normal conditions and, preferably, in various pathologies. Some authors have made similar attempts, but their works are few in number and have not come into widespread acceptance yet (18-19).

A generally accepted indicator of the CRS integrative activity is the Hildebrandt coefficient - the ratio of the heart rate $(\mathrm{HR})$ to the respiratory rate $(\mathrm{RR})$. However, from the point of view of clinicians, it has a low informative value and is not widely used in medical practice. One single cardiorespiratory 
Table 1. Intensity of reactions of the respiratory and cardiovascular systems in low, short-term exercises of increasing capacity

\begin{tabular}{|c|c|c|c|c|c|c|}
\hline $\begin{array}{c}\text { Series/ } \\
\text { Parameter }(M \pm m) \\
\end{array}$ & RV, I & $\begin{array}{c}\text { RR, movements } \\
\text { per min. }\end{array}$ & RMV, I & HR, beats/min. & $\begin{array}{c}\text { Systolic blood } \\
\text { pressure, mm Hg }\end{array}$ & $\begin{array}{c}\text { Diastolic pressure, } \\
\mathrm{mmHg} \\
\end{array}$ \\
\hline \multirow[t]{2}{*}{ 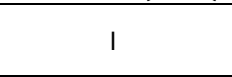 } & $0.63 \pm 0.1$ & $16.14 \pm 1.6$ & $9.92 \pm 1.02$ & $82.6 \pm 5.8^{\star \star}$ & $122.3 \pm 4.81$ & $77.5 \pm 5.1^{\star}$ \\
\hline & $(0.4 \pm 0.07)$ & $(18.4 \pm 1.9)$ & $(8.99 \pm 0.8)$ & $(72.6 \pm 6.2)$ & $(116.1 \pm 8.1)$ & $(73.9 \pm 5.9)$ \\
\hline \multirow{2}{*}{ II } & $0.62 \pm 0.07$ & $16.46 \pm 0.9$ & $10.4 \pm 1.2$ & $78.8 \pm 5.7^{\star \star}$ & $124.55 \pm 4.6$ & $78.6 \pm 5.4^{\star}$ \\
\hline & $(0.5 \pm 0.06)$ & $(18.5 \pm 1.1)$ & $(8.84 \pm 1.0)$ & $(72.0 \pm 6.5)$ & $(118.0 \pm 6.1)$ & $(75.4 \pm 4.8)$ \\
\hline \multirow{2}{*}{ III } & $0.64 \pm 0.11$ & $20.23 \pm 1.7$ & $12.26 \pm 1.3$ & $81.73 \pm 4.6^{\star}$ & $126.14 \pm 6.2$ & $78.65 \pm 5.4^{\star}$ \\
\hline & $(0.5 \pm 0.01)$ & $(17.7 \pm 1.3)$ & $(9.14 \pm 1.2)$ & $(72.0 \pm 6.5)$ & $(115.0 \pm 6.5)$ & $(74.9 \pm 4.9)$ \\
\hline \multirow{2}{*}{ IV } & $0.69 \pm 0.14$ & $20.95 \pm 2.3$ & $13.97 \pm 2.2$ & $86.45 \pm 7.1^{\star}$ & $128.64 \pm 4.7$ & $82.04 \pm 5.9$ \\
\hline & $(0.53 \pm 0.1)$ & $(17.9 \pm 1.9)$ & $(9.27 \pm 1.1)$ & $(75.3 \pm 7.8)$ & $(114.5 \pm 7.4)$ & $(75.4 \pm 8.0)$ \\
\hline \multirow{2}{*}{ V } & $0.65 \pm 0.05$ & $20.18 \pm 1.9$ & $13.94 \pm 0.7$ & $86.41 \pm 6.2$ & $130.68 \pm 5.2$ & $83.86 \pm 5.3$ \\
\hline & $(0.52 \pm 0.1)$ & $(17.1 \pm 1.5)$ & $(8.85 \pm 0.8)$ & $(74.8 \pm 6.7)$ & $(116.1 \pm 6.2)$ & $(75.2 \pm 6.1)$ \\
\hline
\end{tabular}

Notes: the original (at rest) values are shown in parentheses;

${ }^{\star}-p<0.05 ;{ }^{\star \star}-\mathrm{p} \geq 0.05$; in all other cases, $p<0.01$.

index that does not take into account the amplitude of external respiration and the power characteristic of the heart functioning should be considered insufficient. In addition, as shown by our previous studies conducted on cats, the Hildebrandt coefficient remains virtually unchanged when forming baro- and chemoreflexes (17).

In our laboratory, based on experiments on cats and clinical studies on pregnant women, cardiorespiratory indicators were developed, which we described in early publications (16,20-22). Yu.S. Vanyushin (23) proposed the coefficient of complex CRS evaluation, calculated as $\left(\mathrm{SV} \times \mathrm{O}_{2} \mathrm{UC}\right) /(\mathrm{HR} \times \mathrm{RMV})$, where SV - systolic volume, $\mathrm{O}_{2} \mathrm{UC}$ oxygen utilization coefficient, HR - heart rate, RMV - respiratory minute volume. Another indicator used for research purposes is the coefficient of the organism's oxygen supply (24) $\mathrm{CaO}_{2} / \mathrm{CaO}_{2 \mathrm{p}} \times \mathrm{MBFV} / \mathrm{MBFV} \times(\mathrm{SB}+\mathrm{BE}) /(\mathrm{SB}+\mathrm{BE})_{\mathrm{p}}$, which makes it possible to accurately assess the compliance of oxygen delivery to individual metabolic needs. However, difficulties in calculating, obtaining initial data or the lack of volume parameters create significant obstacles to using the abovementioned indices "bedside". In our opinion, the calculation of the CRS activity should be made with mandatory consideration of power characteristics of its functioning. At the same time these coefficients should be informative even for minor reactions, as well as be easy to calculate.

The purpose of the study is: to develop a coefficient for evaluating cardiorespiratory reactions that takes into account both frequency and power characteristics of external respiration and hemodynamics, sensitive to minimal exercises, and to compare its informative value with the generally accepted Hildebrandt coefficient.

\section{MATERIAL AND METHODS}

Five series of studies were conducted on 154 practically healthy people aged 19-23 years, of both sexes, and of different body types. Previously, we collected data for the absence of heart or lung diseases, performed training in involuntary breathing skills with a spirograph and with an imposed pedal rotation mode, as well as informed the subjects about the progress of the study, each of the participants agreed to be involved.

On a stationary bicycle Oxygen Satori U (China), with a pedal rotation rate of 40 per minute, physical activities of standard intensity levels were provided: I - $25 \mathrm{~W}$, II - $50 \mathrm{~W}$, III $75 \mathrm{~W}$, IV - $100 \mathrm{~W}$ and V - $125 \mathrm{~W}$. The effects of physical loads on the body were classified by the Borg method (25-26) and were distributed from extremely insignificant (in the 1st series) to moderate (in the 5th). Spirography (SMP-21/01, Russia), tonometry and heart rate monitoring were performed before the exercises, at their maximum and in 3 minutes after them. The Starr formula was used to calculate the SV (stroke volume output) with subsequent determining the minute blood flow volume (MBFV).

The methods were used in generally accepted ways, and the following adjustments were made. First, the respiratory capacity (RV), RMV, and findings of tonometry and heart rate monitoring were recorded in each observation, on each subject simultaneously. In this case, standardization of research conditions is significantly increased. Since it is impossible to take into account the large number of changes occurring every second in the body that affect the CRS activity. Otherwise measuring the parameters of the cardiovascular and respiratory systems at different time moments can significantly complicate identification of patterns of cardiorespiratory interaction that interest us. Second, a short-term, 60-second cycle ergometer load was used to register initial adaptive responses.

Statistical processing was performed in the MS ${ }^{\circledR}$ Excel ${ }^{\circledR}$ 2016 spreadsheet environment with the Statistica ${ }^{\circledR} 7.0$ package (StatSoft Inc., USA). Differences in Student's $t$-test were accepted as significant at $p<0.01$, in addition, the method of sign test was used (27).

\section{RESULTS AND DISCUSSION}

In the first series, relative to the state of rest, the RV (respiratory volume) increased by approximately $28 \%$, while RR (respiratory rate) decreased by 2.3 movements/min., the increase of RMV was about 10\% (Tables 1 and 2). Systolic and diastolic pressure levels increased less significantly - by 6.16 and $3.64 \mathrm{mmHg}$, respectively (about $5 \%$ as compared with the initial level). That is, hemodynamics was characterized by greater stability and diastolic pressure often did not change. When the load intensity was increased, changes in most parameters preserved their directedness, but became more pronounced. At this, the HR also decreased in the second series, starting to exceed the initial values at rest only from the third series. Pulse changes in series I and II had an invalid tendency to increase by about $6-12$ beats/min (8-16\%).

After stopping providing loads, in 1-3 minutes, in all series, the indices returned to their original values or were close to them. 
Table 2. Changes in systolic volume and minute blood flow volume during bicycle exercise

\begin{tabular}{|c|c|c|c|c|c|c|}
\hline \multirow{2}{*}{$\begin{array}{c}\text { Series/ } \\
\text { Parameter }(\mathrm{M} \pm \mathrm{m})\end{array}$} & \multicolumn{2}{|c|}{ SV, ml } & \multicolumn{2}{|c|}{ MBFV, I } & \multicolumn{2}{|c|}{ The Kerdo Index ${ }^{\star \star}$} \\
\hline & At rest & At maximum load & At rest & At maximum load & At rest & At maximum load \\
\hline I series & $60.13 \pm 4.7$ & $59.51 \pm 4.9^{\star}$ & $4.37 \pm 0.5$ & $4.95 \pm 0.4$ & -1.79 & 6.17 \\
\hline II series & $59.93 \pm 4.9$ & $59.46 \pm 5.1^{\star}$ & $4.35 \pm 0.5$ & $4.7 \pm 0.6$ & -4.72 & 0.25 \\
\hline III series & $58.14 \pm 5.7$ & $57.47 \pm 6.2$ & $4.2 \pm 0.6$ & $4.7 \pm 0.5$ & -4.03 & 3.77 \\
\hline IV series & $56.81 \pm 6.0$ & $54.51 \pm 5.7$ & $4.2 \pm 0.5$ & $4.71 \pm 0.5$ & -0.13 & 5.1 \\
\hline V series & $57.99 \pm 4.6$ & $56.61 \pm 4.9$ & $4.34 \pm 0.4$ & $4.89 \pm 0.5$ & -0.53 & 2.95 \\
\hline
\end{tabular}

Note: ${ }^{\star}-p<0.05$; in all other cases, $p<0.01 ;^{\star \star}$ - calculated from the average values.
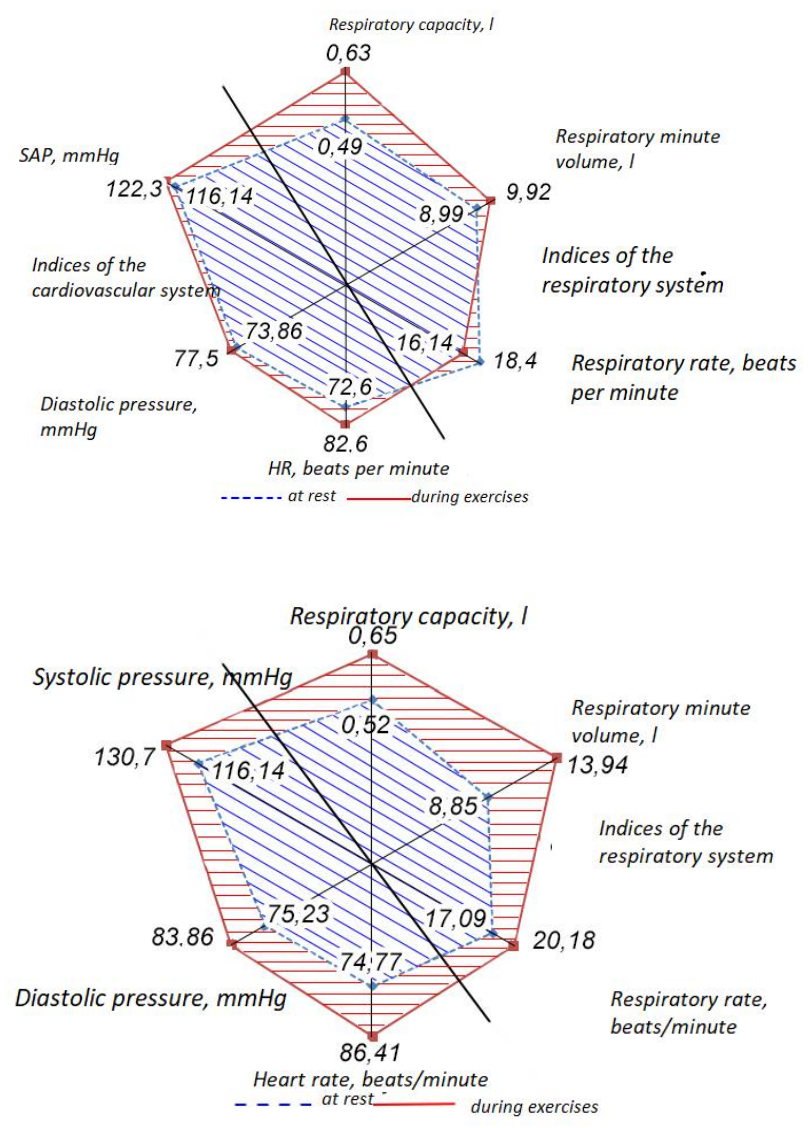

Figure 1. Comparison of the intensity of respiratory and cardiovascular system responses during exercise in the I series ( $25 \mathrm{~W}$; left) and the IV series (125 W; right) series.

Notes: each diagram axis has its own graduation mark; the proportionality of reactions' intensity in each axis is preserved; HR - heart rate; SAP systolic pressure.

The activity of the CRS is an integrative resultant reaction of its numerous components: external respiration, heart activity, tonic activity of arteries and veins (28). Each component is able to react independently, changing the overall adaptive result of blood aeration and its delivery to tissues. What is the possible expediency of obtained in this work greater reactivity of the depth of respiration, observed against the background of suppressing its frequency? Let us pay attention that regardless of the decrease in RR, there was an increase in RMV. In our opinion, from the point of view of energy expediency, it is more effective to change the intensity of pulmonary ventilation not due to the frequency of changes in the acts of inhalation and exhalation, but due to amplitude reactions of each of these acts. The amplitude of respiratory movements turns out to be a more labile value than its frequency. The cardiovascular system turns out to be more rigid under the specified conditions, its parameters changed to a lesser extent (Figure 1), and the HR and the diastolic pressure often had a pronounced scatter of the average.
In all series, the change in the Kerdo index indicated an increase in the sympathetic tone, which corresponds to the entry of an organism into the conditions of physical activity. However, the intensity of changes in this index as loads increased was not proportional to their degree.

Under the given conditions, significant lability of the respiratory system was observed against the background of a relatively stable state of hemodynamics (Figure 2). In the first moments of physical activity, the CRS adaptive reactions are organized to a greater extent by the respiratory type. 


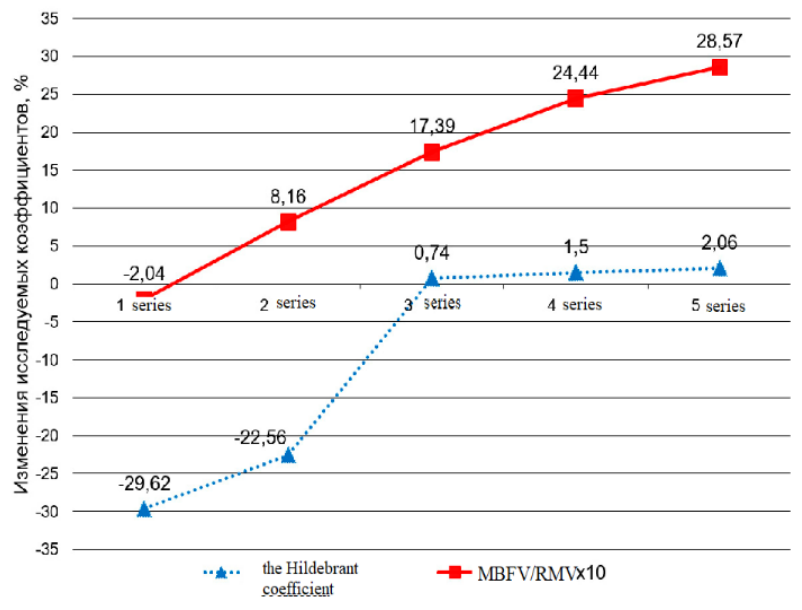

Note: to bring both coefficients to the same order, the CRI was multiplied by 10

Figure 3. Comparison of changes in the cardiorespiratory indexand the Hildebrant coefficient when the body adapts to low physical loads of increasing power (as percentage to their initial values, at rest)

The Hildebrandt coefficient, which characterizes the body's rigid constant - the vegetative status, is normally 2.8-4.9 in humans. In our opinion, this index is not able to adequately reflect the changes that occur during short-term exercises, since the body's vegetative status does not change under such natural stress stimulations. This coefficient does not take into account power cardiorespiratory indicators - RV and SV. According to the results of this study, SV is the most variable value of cardiorespiratory activity. In addition, the decrease in RR which we detected in conditions of minimal loads reduces the informative value content of the Hildebrandt coefficient.

To assess time-sensitive reactions of the CRS, it is necessary to use a coefficient that takes into account power characteristics of its functioning as well (29-30). We have proposed a cardiorespiratory index (CRI) calculated as MBFV/RMV = $(\mathrm{SV} \times \mathrm{HR}) /(\mathrm{RV} \times \mathrm{RR})$. We compared the intensity of changes in CRI and the Hildebrandt coefficient in the given conditions of this survey in relation to their initial (at rest) values (Figure 3).

It can be seen that the CRI is not only labile, but proportional to the conditions of low loads as well. Given that the loads were provided for only 60 seconds, then the sensitivity of this coefficient should be considered high. While the behavior of the Hildebrandt coefficient, while maintaining the general tendency to change, nevertheless has less accuracy.

The obtained results correlate with findings of other researchers. At medium cycle ergometer loads, the contribution of external respiratory reactions to ensuring the body's adaptation to physical labor in the Subarctic was shown to be greater in comparison with the cardiovascular system (31). The CRS reactions formed mainly due to the frequency characteristics of respiration and hemodynamics are less optimal and uneconomical (32). In addition, in hypoxic exposure (6.8-8.0\% of oxygen in the inhaled air), in the first 510 minutes there is a greater increase in the intensity of external respiration against the background of a slight increase in the systolic pressure, the diastolic pressure may even decrease (33-34). For example, in the initial reactions of the CRS (on the 5 th minute out of 20 minutes of the total duration), a

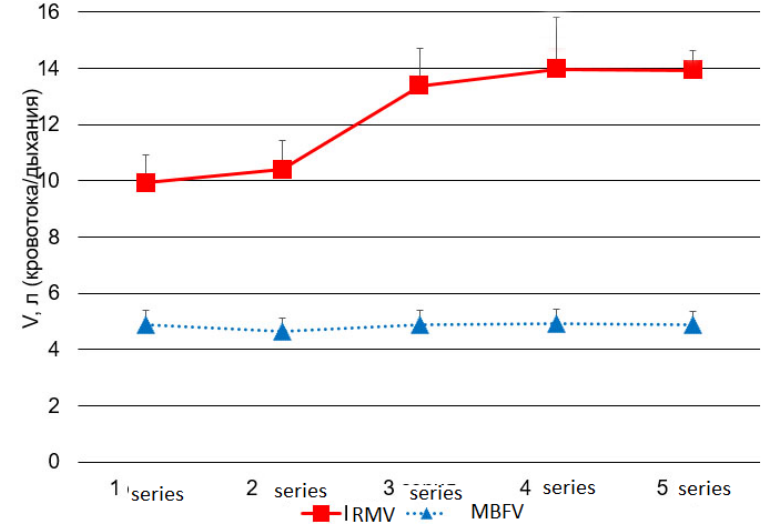

Figure 2. Pronounced variability of respiratory minute volume (upper curve) and low reactivity of minute blood flow volume (bottom) in increasing minor cycle ergometer loads.

greater increase in the RMV and a lower degree of increase in the pulse were registered at such exposure. In addition, in people with hypokinetic type of blood circulation, there is a marked inclusion of external respiration in the adaptive reactions of the CRS, while in people with hyperkinetic type, adaptive activity is mainly achieved due to the chronotropic effect of hemodynamics (35).

The coefficient of the ratio of the MBFV to the RMV, that we propose, adequately, proportionally and quickly reflects even small changes in the state of the CRS. In what way will this coefficient behave in more pronounced, long-term loads? Is it possible to use it in sports medicine, as well as in clinical practice for situational, "at the patient's bedside" diagnostics of corresponding changes? The answers to these questions require further research.

\section{CONCLUSION}

Conditions from minimal to moderate short-term physical exercises determine the dominance of the respiratory component within the CRS. To a lesser extent, adaptation is provided by the cardiovascular system. The least significant changes occur in the frequency activity of the heart. In minimal cycle ergometer loads, increase in the RMV is carried out only due to increasing the RV, while the RR decreases. An increase in both the frequency and power characteristics of external respiration reactions occurs in more intensive loads. The ratio of the MBFV to the RMV, which we called the CRI, adequately reflects changes in cardiorespiratory activity under the specified conditions.

\section{REFERENCES}

1. Aghajanyan NA, Petrov VI, Radish IV, Krayushkin SI. Chronophysiology, chronopharmacology, chronotherapy. Volgograd: Publ. VolGMU; 2005.

2. Sergievskiy MV. Respiratory center of mammals and regulation of its activity. Moscow: Medgiz; 1950.

3. Chernigovskiy VN. Interoceptors. Moscow: Medgiz; 1960. 
4. Gabdrahmanov RSh, Popov YuM, Gordievsraya NA. Central mechanisms of respiratory and cardiovascular systems interaction. Functional organization of the respiratory center and its connection with other systems: Proceedings of all-Union scientific-practical conference. Kuibyshev; 1990:

5. Somers VK, Mark AL, Abboud FM. Interaction of baroreceptor and chemoreceptor reflex control of sympathetic nerve activity in normal humans. J. Clin. Invest, 1991;87:195-203. https://doi.org/10.1172/ JCl115221 PMid:2040688 PMCid:PMC296947

6. Donina ZhA. Intersystemic relationship of respiration and circulation. Fiziologiya cheloveka, 2011;37(2):117-28. https://doi.org/10.1134/S0362119711020034

7. Gerasimov IG, Samohina EV. The relationship between hemodynamic and respiratory parameters in humans. Fiziologiya cheloveka, 2003;29(4):72-5.

8. Ugander M, Jence E, Arheden H. Pulmonary intravascular blood volume changes through the cardiac cycle in healthy volunteers studied by cardiovascular magnetic resonance measurements of arterial and venous flow. J. Cardiovasc. Magn. Reson, 2009;11(1):42-56. https://doi.org/10.1186/ 1532-429X-11-42 PMid:19878570 PMCid:PMC2773236

9. Balikin MV, Karkobatov HD. Systemic and organ mechanisms of the organism oxygen supply in high altitude. Rossiyskiy fiziologicheskiy zhurnal im. I.M. Sechenova, 2012;98(1):127-36.

10. Taylor EW, Leite CA, Sartori MR, Wang T, Abe AS, Crossley $D A$. The phylogeny and ontogeny of autonomic control of the heart and cardiorespiratory interaction in vertebrates. J. Exp. Biol, 2014;217(5):690-703. https://doi.org/10.1242/ jeb.086199 PMid:24574385

11. Breslav IS, Nozdrachev AD. Regulation of breathing: visceral and behavioral components. Uspehi fisiologicheskih nauk, 2007;38(2):26-45

12. Pyatin VF, Tatarnikova VS, Glazkova EN. The role of A5 zone in the control of respiration and circulation during nociceptive stimulation. Proceedings of XX conference of physiology society named after I.P. Pavlov. Moscow; 2007.

13. Arena R, Cahalin LP. Evaluation of Cardiorespiratory Fitness and Respiratory Muscle Function in the Obese Population. Progress in Cardiovascular Diseases, 2014;56(4):457-64. https://doi.org/10.1016/j.pcad.2013.08. 001 PMid:24438738

14. Eskov VM, Eskov VV, Braginskii MYa, Pashnin AS. Determination of the degree of synergism of the human cardiorespiratory system under conditions of physical effort. Measurement Techniques, 2011;54(7):832-7. https://doi.org/10.1007/s11018-011-9812-y

15. Gastinger S, Sorel A, Nicolas G, Gratas-Delamarche A, Prioux JA. Comparison between Ventilation and Heart Rate as Indicator of Oxygen Uptake during Different Intensities of Exercise. J. Sports Sci. Med, 2010;9(1):110-8.

16. Kupriyanov SV, Aghajanyan NA. The role of chemoreceptors of vertebral arteries zone in cardiorespiratory functional system forming. Bulleten' e'ksperimental'noi fiziologii i medicine, 2009;7:4-8. https://doi.org/10.1007/s10517-0090641-9 PMid:19902081

17. Kupriyanov SV, Semenova LM, Bochkarev SV. Principles of cardiorespiratory interaction in realization of chemo- and baroreflexes. The New Armenian Med. J. 2016;10(2):4-13.
18. Lin J, Ngwompo RF, Tilley DG. Development of a cardiopulmonary mathematical model incorporating a baro-chemoreceptor reflex control system. Proc. Inst. Mech. Eng, 2012;226(10):787-803. https://doi.org/10.1177/ 0954411912451823 PMid:23157080

19. Nicolas WA. Comprehensive Cardiopulmonary Simulation Model for the Analysis of Hypercapnic Respiratory Failure. 31st Annual International Conference of the IEEE EMBS. Minneapolis; September 2-6, 2009:5474-7.

20. Kupriyanov SV. The role of baroreceptors of vertebral arteries zone in reflexogenic regulation of splanchnic venous tonus. Bulleten' e'ksperimental'noi fiziologii i medicine, 2009;7:14-7.

21. Kupriyanov SV, Aghajanyan NA. Baroreflexes of the vertebral artery zone on peripheral veins tone, systemic blood pressure and external respiration. Rossiyskiy fiziologicheskiy zhurnal im. I.M. Sechenova, 2008;94(6):6619.

22. Kupriyanov SV, Kupriyanov VS, Drandrov GL, Vodiyanov NG. The role of reflexogenous zones of vertebral and carotid arteries in forming cardio-vascular-respiratory functional system. Vestnik vosstanovitel'noi medicine, 2008;1:78-85.

23. Vanyushin YuS, Khayrullin RR. Cardiorespiratory system as an indicator of functional state of athletes. Teoriya $\mathrm{i}$ praktika fizicheskoy kul'tury, 2015;7:11-4.

24. Vanushin YuS, Vanushin MYu. Interconnection of cardiorespiratory system indices as an innovative way to assess the functionality of athletes. Biologicheskie nauki, 2012;1:148-50.

25. Borg GA. Med. Science Sports Exerc. 1982;14:377-87. https://doi.org/10.1249/00005768-198205000-00012

26. Fletcher GF, Balady GF, Froelicher VF. Exercise standards: a statement for healthcare professionals from the American Heart Association Writing Group. Special Report. Circulation, 1995;91(2):580-615. https://doi.org/10.1161/ 01.CIR.91.2.580 PMid:7805272

27. Kaminskiy LS. Statistical processing of laboratory and clinical data. Leningrad: Meditsina; 1964.

28. Kupriyanov SV. Cardio-vascular-respiratory functionalsystem baroreflexes. Ul'iyanovskiy medico-biologicheskiy zhurnal, 2014;3:80-8.

29. Kupriyanov SV, Bochkarev SV, Semenova L.M. Coefficients for assessing acid-base status changes. Hurry up to do good: Proceedings of interregional scientific-practical conference. Cheboksary, 2016:304-8.

30. Kupriyanov SV, Kupriyanov VS, Semenova LM. Baroreflexes of the vertebral arteries zone. Rossiyskiy fiziologicheskiy zhurnal im. I.M. Sechenova, 2004;90(8):496-506.

31. Gudkov AB, Sarichev AS, Labutin NYu. Reaction of cardiorespiratory system of oil industry workers to expedition work regime in polar region]. E'kologiya cheloveka, 2005;8:43-8.

32. Shostak VI. Actual problems of physiology of military labor. St.Petersburg: Peter; 1992.

33. Soroko SI, Burykh EA. Intrasystemic and Intersystemic Rearrangements of Physiological Parameters in Experimental Acute Hypoxia. Fiziologiya cheloveka, 2004;30(2):58-66. https://doi.org/10.1023/B:HUMP.00000 21646.72315.b4 
34. Burykh EA. Changes of external respiration, brain circulation and the EEG in acute hypoxia in the sublects with different hypoxic resistance. Rossiyskiy fiziologicheskiy zhurnal im. I.M. Sechenova, 2011;97(5):45971.
35. Olyashev NV, Varentsova IA, Pushkina VN. Cardiorespiratory system's indices in young men with different blood circulation types. E'kologiya cheloveka, 2014;4:28-33. 